\title{
Association between retinal vascular caliber and brain structure in schizophrenia
}

Citation for published version (APA):

Korann, V., Appaji, A., Jacob, A., Devi, P., Nagendra, B., Chako, D. M., Padmanabha, A., Thonse, U., Bharath, R. D., Kumar, V., Varambally, S., Venkatasubramanian, G., Rao, S. V., Webers, C. A. B., Berendschot, T. T. J. M., \& Rao, N. P. (2021). Association between retinal vascular caliber and brain structure in schizophrenia. Asian Journal of Psychiatry, 61, [102707].

https://doi.org/10.1016/j.ajp.2021.102707

Document status and date:

Published: 01/07/2021

DOI:

10.1016/j.ajp.2021.102707

Document Version:

Publisher's PDF, also known as Version of record

Document license:

Taverne

Please check the document version of this publication:

- A submitted manuscript is the version of the article upon submission and before peer-review. There can be important differences between the submitted version and the official published version of record.

People interested in the research are advised to contact the author for the final version of the publication, or visit the DOI to the publisher's website.

- The final author version and the galley proof are versions of the publication after peer review.

- The final published version features the final layout of the paper including the volume, issue and page numbers.

Link to publication

\footnotetext{
General rights rights.

- You may freely distribute the URL identifying the publication in the public portal. please follow below link for the End User Agreement:

www.umlib.nl/taverne-license

Take down policy

If you believe that this document breaches copyright please contact us at:

repository@maastrichtuniversity.nl

providing details and we will investigate your claim.
}

Copyright and moral rights for the publications made accessible in the public portal are retained by the authors and/or other copyright owners and it is a condition of accessing publications that users recognise and abide by the legal requirements associated with these

- Users may download and print one copy of any publication from the public portal for the purpose of private study or research.

- You may not further distribute the material or use it for any profit-making activity or commercial gain

If the publication is distributed under the terms of Article $25 \mathrm{fa}$ of the Dutch Copyright Act, indicated by the "Taverne" license above, 


\title{
Association between retinal vascular caliber and brain structure in schizophrenia
}

\author{
Vittal Korann ${ }^{\mathrm{a}}$, Abhishek Appaji $^{\mathrm{b}}$, Arpitha Jacob ${ }^{\mathrm{a}}$, Priyanka Devi ${ }^{\mathrm{a}}$, Bhargavi Nagendra ${ }^{\mathrm{a}}$, \\ Dona Maria Chako ${ }^{a}$, Ananth Padmanabha ${ }^{a}$, Umesh Thonse ${ }^{a}$, Rose Dawn Bharath ${ }^{a}$, \\ Vijay Kumar ${ }^{\mathrm{a}}$, Shivarama Varambally ${ }^{\mathrm{a}}$, Ganesan Venkatasubramanian ${ }^{\mathrm{a}}$, \\ Shyam Vasudeva Rao ${ }^{b}$, Carroll A.B. Webers ${ }^{c}$, Tos T.J.M. Berendschot ${ }^{c}$, Naren P. Rao ${ }^{\mathrm{a}, *}$ \\ ${ }^{a}$ National Institute of Mental Health and Neurosciences, Bangalore, India \\ ${ }^{\mathrm{b}}$ Department of Medical Electronics, BMS College of Engineering, Bangalore, India \\ ${ }^{\mathrm{c}}$ University Eye Clinic Maastricht, Maastricht University, Maastricht, the Netherlands
}

\section{A R T I C L E I N F O}

\section{Keywords:}

Biomarker

fundus photography

Neurodevelopment

Psychosis

Structural MRI

\begin{abstract}
A B S T R A C T
Objective: Several lines of research in the last decade have indicated the potential utility of retina as a window to the brain. Emerging evidence suggests abnormalities in retinal vascular caliber in schizophrenia. However, the relationship between retinal vascular measures and brain structure has not been examined in schizophrenia to date. Hence, we examined the relationship between retinal vasculature measured using fundus photography and brain structure measured using magnetic resonance imaging.

Method: We recruited 17 healthy volunteers and 20 patients with schizophrenia. Using a non-mydriatic camera, we captured the images for left and right eyes separately and retinal vascular calibers were calculated using a semi-automated software package. Whole-brain anatomical T1 MPRAGE images were acquired using a 3-Tesla MRI scanner. Whole-brain and regional volume and cortical thickness were calculated using the Freesurfer software package. We used FreeSurfer's QDEC interface to compute vertex-by-vertex for analysis of the volume and cortical thickness. The relation between brain volume, cortical thickness, and retinal vascular caliber was examined using partial correlation and regression analysis.

Results: There was a significant negative correlation between average CRVE and global cortical mean thickness in schizophrenia but not in healthy. In schizophrenia patients, there was a significant negative correlation between average CRVE and cortical thickness in frontal regions - left rostral middle frontal, left superior frontal, and right caudal middle frontal gyri and posterior brain regions - left lateral occipital gyrus and left posterior cingulate cortex.

Discussion: The findings of the study suggest potential utility of retinal venular diameter as a proxy marker to abnormal neurodevelopment in schizophrenia.
\end{abstract}

\section{Introduction}

Several lines of research in the last decade have indicated the potential utility of retina as a window to the brain to examine the neurobiological aberrations in neuropsychiatric disorders (London et al., 2013; Silverstein and Rosen, 2015). While most of the studies have examined the retinal nerve fiber layer using optical coherence tomography (OCT) (Lizano et al., 2020), a few studies have examined retinal vasculature using fundus photography (Adams and Nasrallah, 2018). Considering the common developmental origin and similar physiological autoregulation properties, retinal vasculature reflects the status of the cerebral vessels (Patton et al., 2005). Though several studies have shown the utility of retinal vasculature examination in neuropsychiatric disorders like stroke, multiple sclerosis, and dementia (London et al., 2013), it is relatively under-examined in schizophrenia. The existing studies in schizophrenia have reported abnormalities in different measures such as vascular caliber, tortuosity, trajectory, and fractal dimension and association with cognitive function (Appaji et al., 2019b, 2019a; Appaji et al., 2019c, 2019a; Appaji et al., 2020; Hosák et al., 2020; Meier et al., 2013). While some of these findings await

\footnotetext{
* Corresponding author at: Department of Psychiatry, National Institute of Mental Health and Neurosciences, Bangalore, India.

E-mail address: docnaren@gmail.com (N.P. Rao).
} 
replication, the increased retinal venular caliber has been reported in several studies even after controlling for systemic risk factors (Appaji et al., 2019a; Hosák et al., 2020; Meier et al., 2013). Besides, wider retinal venules have been reported in unaffected co-twins of schizophrenia patients suggesting the possible developmental nature of these abnormalities (Meier et al., 2015).

While these studies provide the initial evidence for retinal vascular abnormalities in schizophrenia, their relationship with the brain structure or function has not been examined. However, the relationship between retinal vascular measures and brain structure has been examined in other neuropsychiatric disorders and healthy populations. Studies in healthy individuals have reported association between retinal vascular caliber and brain white matter microstructure (Mutlu et al., 2016b), enlarged perivascular spaces (Mutlu et al., 2016a) and decreased white matter volume (Ikram et al., 2013). Association between brain white matter hyperintensity volume and retinal vascular fractal dimension in Alzheimer's dementia (Jung et al., 2019) and an association between retinal nerve fiber layer thickness and gray/white matter volumes in multiple sclerosis, Alzheimer's dementia (den Haan et al., 2018; Saidha et al., 2013) have also been reported. However, one study reported no significant association between cortical atrophy and retinal vascular measures in patients with stroke (Baker et al., 2010).

Two studies have examined the relationship between the retinal nerve fiber layer and structural brain parameters using magnetic resonance imaging in schizophrenia patients. While one study reported an association between the outer nuclear layer thinning and smaller total brain and white matter volumes (Bannai et al., 2020), the other study reported co-impairments in the retinal nerve fiber layer and primary visual cortex but no relation between the two (Zhuo et al., 2020). To date, no study has examined the relationship between retinal vascular caliber and brain structural alterations in schizophrenia patients. The goal of our study was to determine the relationship between retinal vasculature measured using fundus photography and brain structure measured using magnetic resonance imaging (MRI).

\section{Methodology}

\subsection{Subjects}

A total of 37 subjects participated in the study consisting of 17 healthy volunteers (HV) and 20 patients with schizophrenia (SCZ). These subjects are a subgroup of an earlier study that examined the retinal vascular caliber in schizophrenia and bipolar disorder (Appaji et al., 2019a). In addition to the retinal fundus photography, this subgroup underwent an MRI scan, reported in the current study. The mean time period between retinal image acquisition and an MRI scan was 22 days. Details of study criteria and assessments are described in the previous manuscript (Appaji, Abhishek et al., 2019b). In brief, the patients were recruited from the clinical services of the National Institute of Mental Health and neurosciences, Bengaluru, India. All subjects were clinically diagnosed to have a diagnosis of schizophrenia by a psychiatrist as per International classification of Diseases - 10 (World health organization). We excluded patients with a history of substance use disorder, including cannabis, in the past 12 months. However, those with nicotine use disorder were not excluded. Also, those with other concurrent comorbid axis-I psychiatric disorder, lifetime history of hypertension/diabetes mellitus, cerebrovascular accidents, ocular trauma, metal implants in the body, left/mixed handedness or history of electroconvulsive therapy in the past six months were excluded. We also excluded pregnant or lactating women. The healthy volunteers were recruited from the community using flyers, and word of mouth. They were interviewed using SCID-I and those with a diagnosis of any lifetime axis-I disorder were excluded. In addition to the above-mentioned exclusion criteria for patients, we also excluded those with a history of psychosis in first degree relatives. Individuals between 18 and 50 years of age were included. All participants provided written informed consent approved by the institutional ethics committee. The Brief psychiatric rating scale (BPRS) (Overall and Gorham, 1962) equipercentile score was calculated for all subjects (Leucht et al., 2013). We assessed the functioning using the clinical global impression scale (Guy, 1976) and calculated the Olanzapine equivalent for antipsychotics using a previously described method (Leucht et al., 2015). For typical depot antipsychotic medications, Chlorpromazine equivalent was first calculated (Danivas and Venkatasubramanian, 2013) which was later converted to olanzapine equivalent dose.

\subsection{Retinal image acquisition and measurement of retinal vascular caliber}

We followed an established method of acquiring the retinal fundus images. The subject was seated in a dimly lit room for $5 \mathrm{~min}$ for pupillary dilatation. Mydriatic drops were not applied to the participants. Using a non-mydriatic camera, the 3nethra classic (Forus Health pvt. Ltd, Bangalore), we captured the images for left and right eyes separately following a flash of light. The optic disc centered posterior retinal images were captured. The retinal images captured were analyzed using a semi-automated software package - Vessel Assessment and Measurement Platform for Images of the REtina (VAMPIRE). We used a validated method as described in our earlier study (Appaji, Abhishek et al., 2019b). In brief, the optic disc was identified and then the vessel diameter was quantified for the vessels passing through the extended zone. The zone between 0.5 and 2-disc diameters from the optic disc was considered as extended zone. Six largest arterioles and venules were identified, and the vessel diameter was calculated. This method, the revised Knudtson-Parr-Hubbard formula, has improved accuracy than the 3-vessel measurement. The cross-sectional span of the vessel mask perpendicular to the vessel's estimated axis was calculated as the vessel diameter. An iterative process was employed to calculate the Central Retinal Artery Equivalent (CRAE) for arterioles and Central Retinal Vein Equivalent (CRVE) for venules. The values were obtained in pixels and a calibration factor was used to convert these values to micrometers.

\subsection{MRI acquisition and analysis}

The images were acquired using a 3 T MRI scanner (Skyra, Siemens Healthcare, Germany). Whole-brain anatomical T1 MPRAGE images were acquired with the following parameters- $\mathrm{TR}=2200 \mathrm{~ms}$; $\mathrm{TE}=2.45$ $\mathrm{ms}$; Flip angle $=8^{\circ}$; matrix size $=256 * 256$; slice thickness $=1 \mathrm{~mm}$; voxel size $=1 \mathrm{~mm}^{3}$; number of slices $=176$. We used foam pads to reduce the head motion and all subjects with head motion larger than $3 \mathrm{~mm}$ were excluded from the analysis. A radiologist reviewed the structural scans, and none had structural brain abnormalities. We used the standard surface processing pipeline in the FreeSurfer software package, version5.3 (http://surfer.nmr.mgh.harvard.edu) for image processing. In brief, the processing step involved, motion correction, intensity normalization, skull stripping, transformation to MNI template, segmentation, creating the cortical surface and parcellation. We reviewed the images manually to check for accuracy and edited as required during the processing. The resulting thickness, volume and curvature maps were used for further analysis.

\subsection{Statistical analysis}

The demographic variables between the groups were compared using independent $t$-test and chi-square test. In addition to the QDEC analysis described above, we ran a partial correlation between global brain measures (global mean cortical thickness, whole-brain volume, grey matter volume, and white matter volumes) and CRAE/CRVE with age and sex as the covariates. We used age and sex as covariates as there was a significant effect of these variables on cortical thickness and volume (details in supplement). Considering the multiple partial correlations conducted with brain measures (volume and thickness), retinal 
vascular measures (average CRVE and CRAE) and two groups (HV and SCZ), a Bonferroni adjusted $p$ value of $<0.006(0.05 / 8)$ was considered significant. To control for the possible confounding effects of the fasting blood glucose variation, duration of illness and antipsychotic dose we conducted additional partial correlational analysis between these variables and global brain measures/CRAE/CRVE with age and sex as covariates. Also, we conducted a partial correlation between global brain measures and CRAE/CRVE with these variables as covariates in addition to the age and sex of the individual. As two subjects had nicotine dependence, a sub-analysis with a repeat of the partial correlation was conducted after excluding these two subjects.

We used FreeSurfer's QDEC (Query, Design, Estimate, Contrast) interface to perform group averaging and generate the statistical maps. The individual maps were resampled to the fsaverage template in MNI space. From the different methods that QDEC provides to run General liner modelling, we used DODS (different offset, different slope). We performed regression analyses to understand the relation between cortical measures and the retinal vascular measures with age, sex, demeaned ICV as covariates. A Monte Carlo Simulation threshold of 1.3 corresponding to FWE corrected $\mathrm{p}<0.05$ was considered significant.

\section{Results}

\subsection{Groupwise comparison}

The demographics and clinical data are given in Table 1 . There were no significant differences between the groups in age, sex, fasting blood sugar, urea, and creatinine. On GroupWise comparison, SCZ had significantly lower mean cortical thickness compared to HV ( $p=0.001)$. On QDEC analysis, SCZ had significantly lesser volume and area in the left lingual gyrus $(\mathrm{p}=0.001)$ and left inferior parietal lobule $(\mathrm{p}=$ 0.006). There was no significant difference between the groups in whole-brain volume, gray matter volume, white matter volume, CRVE, or CRAE (p > 0.05; Table 1).

\subsection{Association between retinal vascular measures and cortical measures}

On partial correlation, there was a trend level negative correlation between average CRVE and global cortical mean thickness $(r=-0.334$; $\mathrm{p}=0.05$ ). There was a significant negative correlation between average CRVE and global cortical mean thickness in SCZ $(r=-0.65 ; \mathrm{p}=0.003)$ but not in $\mathrm{HV}(\mathrm{r}=0.09 ; \mathrm{p}=0.75)$ suggesting significant difference between the groups in correlation $(\mathrm{z}=2.4 ; \mathrm{p}=0.02)$. We found no

Table 1

Comparison of demographic and clinical features between groups.

\begin{tabular}{|c|c|c|c|c|c|}
\hline & \multicolumn{2}{|c|}{ Schizophrenia } & \multicolumn{2}{|c|}{ Healthy volunteers } & \multirow[t]{2}{*}{$\mathrm{p}$} \\
\hline & Mean & SD & Mean & SD & \\
\hline Age & 31.7 & 5.6 & 29.0 & 5.0 & 0.14 \\
\hline Sex ratio (M:F) & $15: 5$ & & $12: 5$ & & 0.76 \\
\hline DOI & 88.4 & 73.2 & - & - & - \\
\hline CGI & 3.05 & 0.76 & - & - & - \\
\hline BPRS & 30.8 & 7.7 & - & - & - \\
\hline FBS & 98.1 & 13.1 & 96.9 & 10.4 & 0.77 \\
\hline Urea & 18.8 & 7.6 & 21.2 & 6.6 & 0.36 \\
\hline Creatinine & 0.89 & 0.13 & 0.89 & 0.13 & 0.99 \\
\hline CRAE & 103 & 15 & 108 & 19 & 0.35 \\
\hline CRVE & 213 & 27 & 211 & 28 & 0.87 \\
\hline Mean cortical thickness & 2.49 & 0.10 & 2.60 & 0.07 & 0.001 \\
\hline Whole brain volume & 1075 & 62 & 1081 & 103 & 0.86 \\
\hline Gray Matter volume & 602 & 35 & 622 & 60 & 0.23 \\
\hline White matter volume & 424 & 35 & 414 & 49 & 0.49 \\
\hline
\end{tabular}

SCZ- schizophrenia; HV - Healthy volunteer; DOI - Duration of illness; CGI Clinical global impression - severity; BPRS - Brief psychiatric rating scale equipercentile; FBS - fasting blood sugar; CRAE - Central retinal artery equivalent; CRVE - Central retinal vein equivalent; t- independent $t$-test; $\chi^{2}-$ Chisquare test; p- significant at $<0.05$. correlation between average CRAE and global mean cortical thickness ( $\mathrm{p}$ $>0.05$ ) and neither did we find significant correlations between global volumes and CRAE or CRVE (Table 2 and Fig. 1).

On QDEC analysis with age, sex, and demean ICV as covariates, there was a significant negative correlation between average CRVE and thickness of bilateral precuneus in the overall sample (left precuneus $\mathrm{p}=$ 0.05 ; right precuneus $\mathrm{p}=0.04$ ). On further examination for group-wise differences, the relationship was seen only in SCZ; there was a significant negative correlation between average CRVE and cortical thickness in frontal regions - left rostral middle frontal gyrus $(p=0.0001)$, left superior frontal gyrus $(\mathrm{p}=0.007)$, and right caudal middle frontal gyri $(\mathrm{p}=0.032)$ and posterior brain regions - left lateral occipital gyrus ( $\mathrm{p}=$ $0.007)$ and left posterior cingulate cortex $(p=0.0009)$ (Supplement Fig. S1 and S2). There was no significant relationship between average CRVE and regional volume in the overall sample. There was no significant relationship between average CRAE and regional cortical thickness or volume in the overall sample ( $p>0.05$ ). Groupwise correlation between average CRAE and regional cortical thickness and volume are given in supplemental material.

There was no significant relationship between the olanzapine equivalents of the antipsychotic medication, fasting blood sugar, and the global brain measures/CRAE/CRVE (Supplemental table S1). Duration of illness had significant negative correlation with the grey matter volume but had no relation with other variables (supplement Table 1). However, there was no significant effect of these variables on the partial correlation analysis; the correlation between CRVE and global mean cortical thickness remained significant in SCZ even after adding fasting blood sugar, duration of illness and antipsychotic dose as additional covariates (Supplemental table S2). Also, there was no significant effect of nicotine use; even after excluding the two subjects who had nicotine use, the partial correlation between CRVE and mean cortical thickness remained significant (Supplemental Table S3).

\section{Discussion}

To the best of our knowledge, this is the first study to examine the relationship between the retinal vascular caliber and the cortical thickness and volume in patients with schizophrenia. The findings of the study suggest a significant negative correlation between retinal venular caliber and global cortical thickness; the wider venular diameter was associated with the thinner cortex in schizophrenia patients. On regionwise analysis, schizophrenia patients had a significant negative relation between cortical thickness in frontal - occipital regions and retinal venular caliber.

Our findings add to the emerging literature suggesting the utility of retinal changes as a proxy measure for brain structural changes. Our finding of the association of retinal venular diameter with global cortical thickness is comparable to the previous study which reported a thinner

Table 2

Partial correlation analysis showing the relation between global brain measures and retinal vascular caliber.

\begin{tabular}{|c|c|c|c|c|c|c|c|}
\hline & & \multicolumn{3}{|c|}{ Average CRVE } & \multicolumn{3}{|c|}{ Average CRAE } \\
\hline & & SCZ & HV & Total & SCZ & HV & Total \\
\hline \multirow{2}{*}{$\begin{array}{l}\text { Global mean } \\
\text { cortical thickness }\end{array}$} & $\mathrm{r}$ & -0.65 & 0.09 & -0.33 & -0.39 & 0.12 & -0.11 \\
\hline & $\mathrm{p}$ & 0.003 & 0.75 & 0.05 & 0.10 & 0.68 & 0.53 \\
\hline \multirow{2}{*}{$\begin{array}{l}\text { Whole brain } \\
\text { volume }\end{array}$} & $\mathrm{r}$ & 0.30 & -0.49 & -0.07 & 0.30 & 0.24 & -0.07 \\
\hline & $\mathrm{p}$ & 0.22 & 0.07 & 0.68 & 0.22 & 0.39 & 0.68 \\
\hline \multirow{2}{*}{ Gray matter volume } & $\mathrm{r}$ & 0.03 & -0.43 & -0.18 & -0.25 & 0.28 & -0.18 \\
\hline & $\mathrm{p}$ & 0.91 & 0.11 & 0.29 & 0.32 & 0.32 & 0.29 \\
\hline \multirow{2}{*}{$\begin{array}{l}\text { White matter } \\
\text { volume }\end{array}$} & $\mathrm{r}$ & 0.45 & -0.44 & 0.03 & 0.13 & 0.11 & 0.03 \\
\hline & $\mathrm{p}$ & 0.06 & 0.10 & 0.85 & 0.61 & 0.69 & 0.85 \\
\hline
\end{tabular}

SCZ- schizophrenia; HV - Healthy volunteer; CRVE - Central retinal vein equivalent; CRAE - Central retinal artery equivalent; $r$ - Pearson's productmoment correlation coefficient controlling for age and sex; p significant at $<0.05$. 


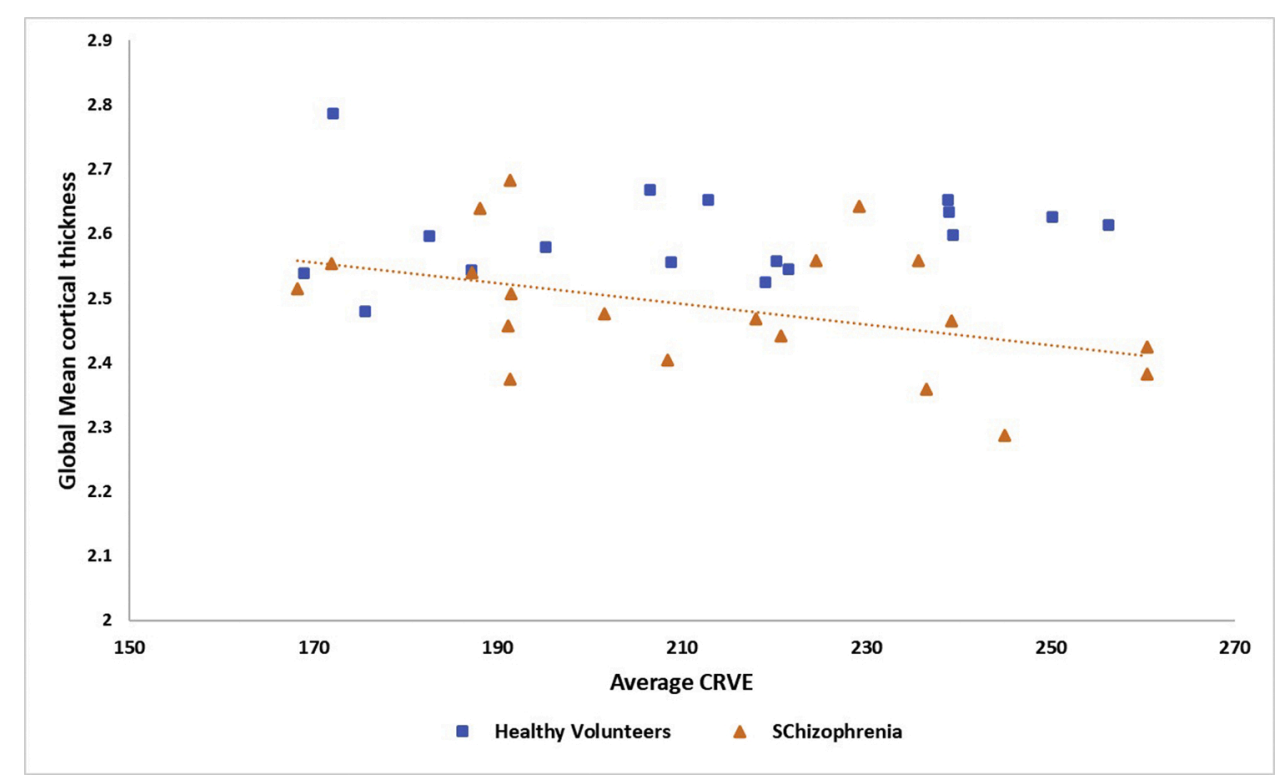

Fig. 1. Scatterplot representing the relation between average CRVE and Global mean cortical thickness.

retina layer to be associated with smaller brain volume (Bannai et al., 2020). In addition to the global brain measures, we also examined the individual regional measures. Our findings suggest a relationship between retinal venular diameter and frontal \& occipital cortical thickness in specific brain regions. Most of the regions that are significantly correlated with retinal venular caliber are implicated in the pathophysiology of schizophrenia; abnormalities in the prefrontal cortex and precuneus-PCC are well-replicated findings in schizophrenia (Keshavan et al., 2020). PFC abnormalities are considered an important feature of schizophrenia and are related to symptom severity, cognitive deficits, and prognosis (Li et al., 2019; Sakurai et al., 2015). Precuneus-PCC is part of the Default Mode Network (DMN), whose aberrations are well documented in schizophrenia (Fransson and Marrelec, 2008). While the occipital cortex is not commonly examined, studies in the recent past have reported the co-impairment of the retina and visual cortex structure in schizophrenia (Zhuo et al., 2020). Hence, the association between PFC-precuneus cortical thickness and retinal venular caliber found in our study, provides further support to the notion of the retina as a mirror to cerebral pathology.

The exact mechanisms linking the retinal vascular changes to brain structural changes are still not completely known. Considering the common developmental origin of retina and brain (Dowling, 2012), the neurodevelopmental aberrations that affect brain development in schizophrenia may influence the development of the retina as well. As the retinal and cerebral microvasculature are tightly linked to each other and have bidirectional communication with the neuronal tissue during development (Patton et al., 2005), the aberrant neuronal development is also possibly reflected in the aberrations of the retinal microvasculature. While these suggest neurodevelopmental mechanisms to be the likely reason, some authors have suggested the possibility of common neurodegenerative mechanisms as well (Frost et al., 2013). Hence, one cannot rule out both neurodevelopmental and neurodegenerative alterations operating in schizophrenia at different point of time, over the course of the illness and may be linked to retinal vascular abnormalities (Keshavan, 1999; Silverstein et al., 2020). Also, one cannot rule out the confounding effects of the medications, comorbid metabolic syndrome which can affect retinal vascular diameter as well as brain cortical thickness (Haijma et al., 2013; Lieberman et al., 2005). However, considering the presence of retinal vascular abnormalities in unaffected co-twins (Meier et al., 2015) and inner plexiform layer thinning in relatives of schizophrenia patients (Kurtulmus et al., 2020) common developmental or degenerative mechanisms are more likely than the epi-phenomenon of confounding factors. On the same line, we do not have an explanation for the absence of relation between CRAE and regional or global cortical thickness. The existing literature on retinal arteriolar caliber in schizophrenia is mixed; while one study suggested narrower arterioles (Appaji et al., 2019a) others have not (Meier et al., 2013). Hence, one cannot rule out the possibility that only CRVE is related to the brain measures but not CRAE. As there was no significant correlation between CRAE and regional cortical thickness in the overall sample, further Groupwise relations cannot be interpreted definitively and need to be considered preliminary. Further studies are needed to elucidate the molecular mechanisms underlying the relation between cortical thickness and retinal vascular caliber.

We did not find a significant difference between the schizophrenia patients and healthy volunteers in the retinal venular caliber or arteriolar caliber. While this finding is contrary to the existing literature, this could be due to sample size. As these participants were part of the larger study which reported wider retinal venules and narrower arterioles (Appaji et al., 2019a), the smaller sample size of the current study is a possible reason. Nonetheless, it is important to note that the directionality of this subsample was similar to the bigger sample used in the earlier study; SCZ had narrower arterioles and wider venules compared to HV. Another possible reason for this absence of group difference is the stringent selection criteria followed in the study. As this is the first study to examine the retinal vascular features and brain measures, we excluded confounding variables like presence of diabetes mellitus and hypertension. While the exclusion of these comorbidities ruled out the confounding effect, they also decreased the representativeness of the patient population. As these disorders and other related disorders including metabolic syndrome are common comorbidities in schizophrenia (Mitchell et al., 2013), it is possible that selecting a population without these comorbidities would have resulted in recruitment of a sub-set of patients who are less severely ill. As a considerable overlap is seen in risk genes for schizophrenia and these metabolic disorders (Moises et al., 2015; Postolache et al., 2019), it is possible that these disorders are related to each other by shared pathophysiology than a chance comorbidity. Hence exclusion of these comorbidities may result in healthier patients and may not represent the entire spectrum of schizophrenia patients. Future studies need to consider including patients with comorbidities and account for the confounding effect statistically.

The findings of the study could have important implications. Our study findings fill an important gap in the existing literature - direct 
evidence for the relationship between retinal vascular caliber and brain structural measures in schizophrenia. Our finding of the correlation between retinal venular diameter and cortical thickness provides the required rationale to use retinal vascular examination as a proxy marker for brain pathology in schizophrenia. Considering the non-invasive nature and affordability of retinal fundus photography, it can be used in a larger number of individuals with minimal operational cost. Also, the portable nature of the equipment allows its use in the community. As the abnormalities in PFC and precuneus-PCC, are determinants of prognosis future longitudinal studies need to examine whether the retinal venular caliber can predict the prognosis or treatment response of an individual which could have important clinical implications. If proven in longitudinal studies, retinal vascular examination could help to screen and prognosticate the individuals in the community.

Our study has a few limitations which need to be considered while interpreting the findings. The sample size of the study was small. Since the current study is the first of its kind, we examined a small sample for proof of concept and our findings need to be treated as preliminary. Future studies with a large sample size need to replicate these findings for definitive evidence. We accounted for several confounding factors that may affect the findings of the study (Silverstein et al., 2020). Those with diabetes mellitus, hypertension, and active substance use including cannabis were excluded, as they are known to affect the retinal vascular measures. None of the subjects had renal impairment. Moreover, there was no relationship between FBS values and retinal/brain structural measures. While the inclusion of people without nicotine use would have controlled the confounding effect of nicotine, it would have affected the generalizability. Considering the prevalence of nicotine use in schizophrenia patients, we did not exclude patients with a history of nicotine use. It is important to note that the findings remained significant even after excluding the two people with nicotine use. We did not exclude people with obesity or measure the body mass index of the patients. However, considering the absence of relation with retinal vascular measures in a recent study and our previous study of which the current study subjects were drawn, it is not likely to be the sole contributor to the findings (Appaji, Abhishek et al., 2019b; Bannai et al., 2020). Nonetheless, future studies need to examine the effect of obesity on the relation between brain measure and retinal vascular caliber in schizophrenia. Studies may consider formally measuring the body mass index or waist circumference and control for the possible confounding effect statistically. Another limitation of the study is using the clinical interview for the diagnosis of patients. Using a structured instrument would have added to the methodological rigor as well as enabled selection of a patient population which is more homogenous, resulting in larger differences between patient and control group. Future studies need to consider using a structured instrument to verify the diagnosis. Finally, the effect of antipsychotic medication on retinal vascular measures is not known but may affect brain structural measures (Lieberman et al., 2005). However, there was no significant influence of the medication dose in this study. Future studies in drug-naïve individuals could overcome the confounding effect of antipsychotics.

To summarise, the study findings suggest a significant inverse relationship between retinal venular caliber and cortical thickness in schizophrenia. The relation between retinal vasculature and brain structure provides further support to the emerging literature suggesting that the retina is a window to the brain. The preliminary results from the current study, if replicated in future studies with larger sample size, could have important implications. Considering the non-invasiveness, affordability, and portability of retinal fundus examination this could potentially serve as a proxy alternative for neuroimaging assessments in resource-constrained communities.

\section{Contributors}

NPR, AA, TB were involved in the conceptualization of the study, design of the study, interpretation of results and manuscript preparation. RDB, VK, SV, GV, SVR, CW were involved in interpretation of results and manuscript preparation. VK was involved in data collection, data analysis, interpretation of results. AA, PS, BN, DC, AP, UT were involved in data collection and data analysis. VK and NPR wrote the first draft of the manuscript and all authors contributed to revisions. All authors have approved the final manuscript.

\section{Funding source}

Department of Science and Technology, Government of India - (PIDr. Naren P Rao; IFA/12/LSBM/36; SR/CSRI/138/2015; SR/SATYAM/ $304 / 2015)$. The funding agency had no role in the interpretation of data or manuscript preparation.

\section{Declaration of Competing Interest}

Dr Shyam Vasudeva Rao is co-founder and Director of Forus Health Pvt Ltd. Other authors report no conflict of interest.

\section{Acknowledgement}

None.

\section{Appendix A. Supplementary data}

Supplementary material related to this article can be found, in the online version, at doi:https://doi.org/10.1016/j.ajp.2021.102707.

\section{References}

Adams, S.A., Nasrallah, H.A., 2018. Multiple retinal anomalies in schizophrenia. Schizophr. Res. 195, 3-12. https://doi.org/10.1016/j.schres.2017.07.018.

Appaji, A., Nagendra, B., Chako, D.M., Padmanabha, A., Hiremath, C.V., Jacob, A., Varambally, S., Kesavan, M., Venkatasubramanian, G., Rao, S.V., Webers, C.A.B., Berendschot, T.T.J.M., Rao, N.P., 2019a. Retinal vascular abnormalities in schizophrenia and bipolar disorder: a window to the brain. Bipolar Disord. 21 https://doi.org/10.1111/bdi.12779.

Appaji, A., Nagendra, B., Chako, D.M., Padmanabha, A., Jacob, A., Hiremath, C.V., Varambally, S., Kesavan, M., Venkatasubramanian, G., Rao, S.V., Webers, C.A.B., Berendschot, T.T.J.M., Rao, N.P., 2019b. Retinal vascular tortuosity in schizophrenia and bipolar disorder. Schizophr. Res. $212 \mathrm{https}$ ///doi.org/10.1016/j. schres.2019.08.020.

Appaji, Abhishek, Nagendra, B., Chako, D.M., Padmanabha, A., Jacob, A., Hiremath, Cv., Varambally, S., Kesavan, M., Venkatasubramanian, G., Rao, Sv., Webers, C.A.B., Berendschot, T.T.J.M., Rao, N.P., 2019c. Examination of retinal vascular trajectory in schizophrenia and bipolar disorder. Psychiatry Clin. Neurosci. 73, 738-744. https://doi.org/10.1111/pcn.12921.

Appaji, A., Nagendra, B., Chako, D.M., Padmanabha, A., Jacob, A., Hiremath, C.V., Varambally, S., Kesavan, M., Venkatasubramanian, G., Rao, S.V., Webers, C.A.B., Berendschot, T.T.J.M., Rao, N.P., 2020. Relation between retinal vascular abnormalities and working memory impairment in patients with schizophrenia and bipolar disorder. Asian J. Psychiatr. 49 https://doi.org/10.1016/j.ajp.2020.101942.

Appaji, Abhishek, Nagendra, B., Chako, D.M., Padmanabha, A., Hiremath, Cv., Jacob, A., Varambally, S., Kesavan, M., Venkatasubramanian, G., Rao, S.V., Webers, C.A.B., Berendschot, T.T.J.M., Rao, N.P., 2019a. Retinal vascular fractal dimension in bipolar disorder and schizophrenia. J. Affect. Disord. 259, 98-103. https://doi.org/ 10.1016/j.jad.2019.08.061.

Appaji, Abhishek, Nagendra, B., Chako, D.M., Padmanabha, A., Hiremath, Cv., Jacob, A., Varambally, S., Kesavan, M., Venkatasubramanian, G., Rao, Sv., Webers, C.A.B., Berendschot, T.T.J.M., Rao, N.P., 2019b. Retinal vascular abnormalities in schizophrenia and bipolar disorder: a window to the brain. Bipolar Disord. 21, 634-641. https://doi.org/10.1111/bdi.12779.

Baker, M.L., Wang, J.J., Liew, G., Hand, P.J., de Silva, D.A., Lindley, R.I., Mitchell, P., Wong, M.C., Rochtchina, E., Wong, T.Y., Wardlaw, J.M., Hankey, G.J., 2010. Differential associations of cortical and subcortical cerebral atrophy with retinal vascular signs in patients with acute stroke. Stroke 41, 2143-2150. https://doi.org/ 10.1161/STROKEAHA.110.594317.

Bannai, D., Lizano, P., Kasetty, M., Lutz, O., Zeng, V., Sarvode, S., Kim, L.A., Hill, S., Tamminga, C., Clementz, B., Gershon, E., Pearlson, G., Miller, J.B., Keshavan, M., 2020. Retinal layer abnormalities and their association with clinical and brain measures in psychotic disorders: a preliminary study. Psychiatry Res. Neuroimag. 299 https://doi.org/10.1016/j.pscychresns.2020.111061.

Danivas, V., Venkatasubramanian, G., 2013. Current perspectives on chlorpromazine equivalents: comparing apples and oranges! Indian J. Psychiatry. https://doi.org/ 10.4103/0019-5545.111475.

den Haan, J., Janssen, S.F., van de Kreeke, J.A., Scheltens, P., Verbraak, F.D., Bouwman, F.H., 2018. Retinal thickness correlates with parietal cortical atrophy in 
early-onset Alzheimer's disease and controls. Alzheimer's Dementia: Diagnosis Assessment Dis. Monitoring 10, 49-55. https://doi.org/10.1016/j. dadm.2017.10.005.

Dowling, J., 2012. The Retina — John E. Dowling. Harvard University Press. Belknap Press, Cambridge.

Fransson, P., Marrelec, G., 2008. The precuneus/posterior cingulate cortex plays a pivotal role in the default mode network: evidence from a partial correlation network analysis. NeuroImage 42, 1178-1184. https://doi.org/10.1016/j. neuroimage.2008.05.059.

Frost, S., Kanagasingam, Y., Sohrabi, H., Vignarajan, J., Bourgeat, P., Salvado, O., Villemagne, V., Rowe, C.C., Lance MacAulay, S., Szoeke, C., Ellis, K.A., Ames, D., Masters, C.L., Rainey-Smith, S., Martins, R.N., 2013. Retinal vascular biomarkers for early detection and monitoring of Alzheimer's disease. Transl. Psychiatry 3. https:// doi.org/10.1038/tp.2012.150 e233-e233.

Guy, W., 1976. Clinical Global Impression Scale: ECDEU Assessment Manual for Psychopharmacology. U.S. Dept. of Health, Education, and Welfare, Rockville.

Haijma, Sv., van Haren, N., Cahn, W., Koolschijn, P.C.M.P., Hulshoff Pol, H.E., Kahn, R. S., 2013. Brain volumes in schizophrenia: a meta-analysis in over 18000 subjects. Schizophr. Bull. 39, 1129-1138. https://doi.org/10.1093/schbul/sbs118.

Hosák, L., Zeman, T., Studnička, J., Stepanov, A., Ustohal, L., Michalec, M., Lochman, J. Jurečka, T., Sadykov, E., Goswami, N., de Boever, P., Balcar, V.J., Šerý, O., 2020. Retinal arteriolar and venular diameters are widened in patients with schizophrenia. Psychiatry Clin. Neurosci. https://doi.org/10.1111/pcn.13123.

Ikram, M.K., de Jong, F.J., Vernooij, M.W., Hofman, A., Niessen, W.J., van der Lugt, A., Klaver, C.C., Ikram, M.A., 2013. Retinal vascular calibers associate differentially with cerebral gray matter and white matter atrophy. Alzheimer Dis. Assoc. Disord 27, 351-355. https://doi.org/10.1097/WAD.0b013e31829344ed.

Jung, N.Y., Han, J.C., Ong, Y.T., Cheung, C.Ylui, Chen, C.P., Wong, T.Y., Kim, H.J., Kim, Y.J., Lee, J., Lee, J.S., Jang, Y.K., Kee, C., Lee, K.H., Kim, E.J., Seo, S.W., Na, D. L., 2019. Retinal microvasculature changes in amyloid-negative subcortical vascular cognitive impairment compared to amyloid-positive Alzheimer's disease. J. Neurol. Sci. 396, 94-101. https://doi.org/10.1016/j.jns.2018.10.025.

Keshavan, M.S., 1999. Development, disease and degeneration in schizophrenia: a unitary pathophysiological model. J. Psychiatr. Res. 33, 513-521. https://doi.org/ 10.1016/S0022-3956(99)00033-3.

Keshavan, M.S., Collin, G., Guimond, S., Kelly, S., Prasad, K.M., Lizano, P., 2020. Neuroimaging in schizophrenia. Neuroimaging Clin. N. Am. 30, 73-83. https://doi. org/10.1016/j.nic.2019.09.007.

Kurtulmus, A., Elbay, A., Parlakkaya, F.B., Kilicarslan, T., Ozdemir, M.H., Kirpinar, I., 2020. An investigation of retinal layer thicknesses in unaffected first-degree relatives of schizophrenia patients. Schizophr. Res. 218, 255-261. https://doi.org/10.1016/j. schres.2019.12.034.

Leucht, S., Rothe, P., Davis, J.M., Engel, R.R., 2013. Equipercentile linking of the BPRS and the PANSS. Eur. Neuropsychopharmacol. 23, 956-959. https://doi.org/ 10.1016/j.euroneuro.2012.11.004.

Leucht, S., Samara, M., Heres, S., Patel, M.X., Furukawa, T., Cipriani, A., Geddes, J., Davis, J.M., 2015. Dose equivalents for second-generation antipsychotic drugs: the classical mean dose method. Schizophr. Bull. 41, 1397-1402. https://doi.org/ 10.1093/schbul/sbv037.

Li, M., Li, X., Das, T.K., Deng, W., Li, Y., Zhao, L., Ma, X., Wang, Y., Yu, H., Meng, Y., Wang, Q., Palaniyappan, L., Li, T., 2019. Prognostic utility of multivariate morphometry in schizophrenia. Front. Psychiatry 10. https://doi.org/10.3389/ fpsyt.2019.00245.

Lieberman, J.A., Tollefson, G.D., Charles, C., Zipursky, R., Sharma, T., Kahn, R.S., Keefe, R.S.E., Green, A.I., Gur, R.E., McEvoy, J., Perkins, D., Hamer, R.M., Gu, H., Tohen, M., 2005. Antipsychotic drug effects on brain morphology in first-episode psychosis. Arch. Gen. Psychiatry 62, 361-370. https://doi.org/10.1001/ archpsyc.62.4.361.

Lizano, P., Bannai, D., Lutz, O., Kim, L.A., Miller, J., Keshavan, M., 2020. A meta-analysis of retinal cytoarchitectural abnormalities in schizophrenia and bipolar disorder. Schizophr. Bull. 46, 43-53. https://doi.org/10.1093/schbul/sbz029.
London, A., Benhar, I., Schwartz, M., 2013. The retina as a window to the brain-from eye research to CNS disorders. Nat. Rev. Neurol. 9, 44-53. https://doi.org/10.1038/ nrneurol.2012.227.

Meier, M.H., Shalev, I., Moffitt, T.E., Kapur, S., Keefe, R.S.E., Wong, T.Y., Belsky, D.W., Harrington, H.L., Hogan, S., Houts, R., Caspi, A., Poulton, R., 2013. Microvascular abnormality in schizophrenia as shown by retinal imaging. Am. J. Psychiatry 170, 1451-1459. https://doi.org/10.1176/appi.ajp.2013.13020234.

Meier, M.H., Gillespie, N.A., Hansell, N.K., Hewitt, A.W., Hickie, I.B., Lu, Y., McGrath, J., MacGregor, S., Medland, S.E., Sun, C., Wong, T.Y., Wright, M.J., Zhu, G., Martin, N. G., Mackey, D.A., 2015. Retinal microvessels reflect familial vulnerability to psychotic symptoms: a comparison of twins discordant for psychotic symptoms and controls. Schizophr. Res. 164, 47-52. https://doi.org/10.1016/j. schres.2015.01.045.

Mitchell, A.J., Vancampfort, D., Sweers, K., van Winkel, R., Yu, W., de Hert, M., 2013. Prevalence of metabolic syndrome and metabolic abnormalities in schizophrenia and related disorders-a systematic review and meta-analysis. Schizophr. Bull. https:// doi.org/10.1093/schbul/sbr148.

Moises, H.W., Wollschläger, D., Binder, H., 2015. Functional genomics indicate that schizophrenia may be an adult vascular-ischemic disorder. Transl. Psychiatry 5. https://doi.org/10.1038/tp.2015.103.

Mutlu, U., Adams, H.H.H., Hofman, A., van der Lugt, A., Klaver, C.C.W., Vernooij, M.W., Ikram, M.K., Ikram, M.A., 2016a. Retinal microvascular calibers are associated with enlarged perivascular spaces in the brain. Stroke 47, 1374-1376. https://doi.org/ 10.1161/STROKEAHA.115.012438.

Mutlu, U., Cremers, L.G.M., de Groot, M., Hofman, A., Niessen, W.J., van der Lugt, A., Klaver, C.C.W., Ikram, M.A., Vernooij, M.W., Ikram, M.K., 2016b. Retinal microvasculature and white matter microstructure. Neurology 87, 1003-1010. https://doi.org/10.1212/WNL.0000000000003080.

Overall, J.E., Gorham, D.R., 1962. The brief psychiatric rating scale. Psychol. Rep. 10, 799-812. https://doi.org/10.2466/pro.1962.10.3.799.

Patton, N., Aslam, T., MacGillivray, J., Pattie, a, Deary, I., Dhillon, B., 2005. Retinal vascular image analysis as a potential screening tool for cerebrovascular disease. J. Anat. 206, 318-348.

Postolache, T.T., del Bosque-Plata, L., Jabbour, S., Vergare, M., Wu, R., Gragnoli, C., 2019. Co-shared genetics and possible risk gene pathway partially explain the comorbidity of schizophrenia, major depressive disorder, type 2 diabetes, and metabolic syndrome. Am. J. Med. Genet. Part B Neuropsychiatr. Genet. https://doi. org/10.1002/ajmg.b.32712.

Saidha, S., Sotirchos, E.S., Oh, J., Syc, S.B., Seigo, M.A., Shiee, N., Eckstein, C., Durbin, M.K., Oakley, J.D., Meyer, S.A., Frohman, T.C., Newsome, S., Ratchford, J. N., Balcer, L.J., Pham, D.L., Crainiceanu, C.M., Frohman, E.M., Reich, D.S., Calabresi, P.A., 2013. Relationships between retinal axonal and neuronal measures and global central nervous system pathology in multiple sclerosis. Arch. Neurol. 70, 34-43. https://doi.org/10.1001/jamaneurol.2013.573.

Sakurai, T., Gamo, N.J., Hikida, T., Kim, S.H., Murai, T., Tomoda, T., Sawa, A., 2015. Converging models of schizophrenia - Network alterations of prefrontal cortex underlying cognitive impairments. Prog. Neurobiol. 134, 178-201. https://doi.org/ 10.1016/j.pneurobio.2015.09.010.

Silverstein, S.M., Rosen, R., 2015. Schizophrenia and the eye. Schizophr. Res. Cogn. 2, 46-55. https://doi.org/10.1016/j.scog.2015.03.004.

Silverstein, S.M., Fradkin, S.I., Demmin, D.L., 2020. Schizophrenia and the retina: towards a 2020 perspective. Schizophr. Res. 219, 84-94. https://doi.org/10.1016/j. schres.2019.09.016.

Zhuo, C., Xiao, B., Ji, F., Lin, X., Jiang, D., Tian, H., Xu, Y., Wang, W., Chen, C., 2020. Patients with first-episode untreated schizophrenia who experience concomitant visual disturbances and auditory hallucinations exhibit co-impairment of the brain and retinas-a pilot study. Brain Imaging Behav. 1-9. https://doi.org/10.1007/ s11682-020-00351-1. 